\title{
Social and Environmental Responsibility in Small and Medium Enterprises in Latin America
}

\author{
Antonio Vives
}

Inter-American Development Bank

Washington, D.C.

Sustainable Development Department Technical Papers Series 


\section{Cataloguing-in-Publication provided by Inter-American Development Bank Felipe Herrera Library}

Vives, Antonio.

Social and environmental responsibility in small and medium enterprises in Latin America / Antonio Vives.

p.cm.

(Sustainable Development Department Technical papers series ; PEF-105)

Includes bibliographical references.

1. Social responsibility of business - Latin America. 2. Environmental responsibilityLatin America. 3. Small business-Latin America. I. Inter-American Development Bank. Sustainable Development Dept. Private Enterprise and Financial Markets SubDept. II. Title. III. Series.

\section{$658.408 \mathrm{~V} 225-\mathrm{dc} 22$}

Antonio Vives is Deputy Manager of the Private Enterprise and Financial Markets Subdepartment, Sustainable Development Department, at the Inter-American Development Bank, in charge of policies, strategies and best practices on the contribution of the private sector to economic development. He is the author of a book on corporate financial evaluation and numerous articles in private participation in infrastructure, financial markets development and CSR. He is the Chair of the organizing committee of the series of Inter-American Conferences on Corporate Social Responsibility and editor of the Proceedings. He holds a Ph.D. in corporate finance from Carnegie Mellon University.

The opinions expressed herein are those of the authors and do not necessarily reflect the official position of the Inter-American Development Bank. Permission is granted to reproduce this paper in whole or in part for non-commercial purposes only and with proper attribution to the author, the Sustainable Development Department, and the Inter-American Development Bank.

September 2005

This publication (Reference No. PEF-105) can be obtained from:

Private Enterprise and Financial Markets Subdepartment

Sustainable Development Department

Inter-American Development Bank

Stop W-0504

1300 New York Ave, NW

Washington, D.C. 20577

E-mail: $\quad$ antoniov@iadb.org

Fax: 202-623-1708

Web Site: $\quad$ www.iadb.org/sds 


\section{Foreword}

Responsible practices by private firms have been under careful scrutiny in the last few years, mostly as a result of a few very visible cases of corporate misgovernance. Unease with the narrower issue of corporate governance has reinforced the concerns of governments and (especially) civil society regarding the relationship between firms, society and the environment in which they operate. These concerns have arisen in the context of increasing globalization resulting pressures to remain competitive. In the opinion of many, this has led to heightened risks of misbehavior by private firms.

At the same time, concern about the prevalence poverty and underdevelopment in many countries has highlighted the importance of engaging the private sector in assisting governments to solve these problems, in particular, the achievement of the Millennium Development Goals. All these factors have led to a resurgence of the concerns with the issue of corporate social responsibility (CSR), which in its broader view, refers to the actions that firms take to carry out their activities in a responsible manner, respecting the environment, the community and the workforce, and also creating opportunities to enhance them.

Most of the concerns have been directed at large firms, presumably because they are the most visible and have the highest impact. The literature has tended to ignore small and medium enterprises (SMEs). However, as this paper points out, SMEs represent over 95 percent of all firms in Latin America, provide between 40 and 60 percent of all jobs, and account for 30 to 50 percent of GDP. As a result, responsible behavior by these firms can also have a significant impact on society and the environment.

The study summarized in this paper sought to determine the extent to which SMEs behave responsibly and, based on the results, propose measures to enhance responsible behavior. The study is quite comprehensive, covering eight countries in Latin America and over 1,300 firms. We hope

that it will contribute to further the development of research and policies to foster the responsible behavior of SMEs and, in turn, enhance their contribution to economic development.

Carlos M. Jarque

Manager

Sustainable Development Department 


\title{
Contents
}

\author{
Introduction
}

1

Social and Environmental Responsibility in Small and Medium Enterprises in Latin America

3

Fostering Corporate Social Responsibility in SMEs

11

References

13 


\section{Introduction}

\section{CORPORATE SOCIAL RESPONSIBILITY IN SMALL AND MEDIUM ENTERPRISES}

Small and medium enterprises (SMEs) make up more than 90 percent of businesses worldwide and account for between 50 and 60 percent of employment. In Latin America, 95 percent of firms are SMEs, and account for between 40 and 60 percent of jobs, depending on the country, and contribute 30 to 50 percent of GDP. In the European Union, it is estimated that, as of 2003, more than 20 million SMEs (with up to $250 \mathrm{em}$ ployees) accounted for over 80 million jobs. In the United States (where small firms are defined as those having fewer than 500 employees), 99.7 percent of all firms fall into the "small business" category, account for half the nation's jobs and contribute more than 50 percent of nonfarm GDP.

Because these firms tend to be more labor intensive than large enterprises, they have a significant impact on employment and, as a result, their corporate social responsibility practices have a significant impact on society as whole, even if their contribution to the overall production of goods and services is not as large. In addition, they tend to contribute more to the equitable distribution of income and, because they provide employment and income to the less well off, they help to provide social cohesion and stability. Together, these reasons make promoting socially responsible SMEs a topic of rising importance.

However, it is first necessary that we understand the special characteristics of small and medium enterprises. SMEs are very different from the larger businesses for which most of the concepts and methodologies of CSR have been developed. SMEs have very different stakeholders. In particular, many are family-owned firms, or are privately held by a small group of shareholders, particularly in emerging economies. This close relationship between management and ownership makes it easier to align the objectives of both. Thus, SME activities may reflect the values, character, attitudes, education, background and the like of the owner/entrepreneur. This will have a direct impact in the firm's corporate responsibility.

The generalized assumption that maximizing profits is the main objective of larger firms may not be true for SMEs. Given the assumption of profit maximization, CSR practices in larger corporations are promoted by appealing to the bottom line (either currently or in the future, tangibly or intangibly). Yet, many SMEs may not operate as profit maximizing firms and may, in fact, also have other objectives. This is not to say that SMEs are not concerned with profits. It means that they may be willing to forego some profits (knowingly or unknowingly) to achieve other objectives, such as producing products that the owners/managers find satisfying to make, giving back to society, helping others who are less fortunate, and other such goals. The point is that "satisfactory" profits (rather than "maximum" profits) may be sufficient, and they may be willing to trade off some profit for other goals. ${ }^{1}$ This has implications for the strategies used to promote CSR practices in SMEs: the business case may be important, but it may not be critical, as they will also react to enlightened self interest, to social conscience stimuli and altruistic reasons. Also, given the resource constraints (time, money and qualified personnel) faced by SMEs, they also are more vulnerable to economic conditions and their CSR activities will shift with the economic cycle.

Most SMEs tends to serve local markets and are not exposed to international pressures or incentives. In addition, civil society organizations will not be very concerned with their actions, preferring to devote their limited resources to the "big fish," that is, the larger corporations that have a greater impact. Nevertheless, some SMEs sell their products and services internationally and to

\footnotetext{
${ }^{1}$ These results are highlighted in recent studies carried out by the Inter-American Development Bank. See Kantis et al. (2002) and Kantis et al. (2004).
} 
larger corporations, many of which are concerned about the extent to which their suppliers are socially responsible.

In general, SMEs by their very nature are local institutions whose owners/managers, customers and workers come from the same community. Because SMEs have relatively few employees, many of them are known to the managers and owners, leading to a more tangible concern for their well-being. It should be natural for these firms to be concerned with community development, the local environmental and social issues; although for lack of knowledge, economic reasons or fear or regulations may not be as involved as it would be expected.

SMEs normally struggle to survive under adverse economic conditions and, as a result, regulations tend to be more burdensome for them than for larger corporations. The implications of social and environmental concerns and regulations are likely to make SME owners and managers quite anxious because they will perceive them as an additional burden (unless the business case is made in a language and form that they can understand). As with larger enterprises, SMEs must be shown that CSR can be tool to increase competitiveness. However, while the reasons might be similar, the emphasis will be very different. It will be less a matter of education and more an issue of awareness and changing perceptions over the implications of CSR for the enterprise.

\section{SMALL AND MEDIUM ENTERPRISES IN LATIN AMERICA}

The productive structure of Latin American SMEs is heavily polarized. Some larger enterprises (mostly those in the natural resources and extractive industries) enjoy international exposure, while a very large number of SMEs are mostly concerned with local markets, at best supplying large international firms. In general, the middle sector is much less developed than is the case for SMEs in developed economies. Similarly, productivity is much lower than that of the larger firms. The productivity of SMEs in developed economies, however, is much closer to that of large enterprises. Latin American
SMEs are less specialized, and generally function as lower capacity suppliers to larger firms that have a high value added. Furthermore, as a result of having a lower birth rate, being less innovative and technologically advanced, and geared more towards commerce than manufacture, SMEs in Latin America tend to be "older" than in other regions.

In general, Latin American SMEs, and particularly smaller firms, are also characterized by low capital intensity. In addition, owners, partners and their families tend to participate as part of the labor force. This makes them extremely dependent on the owners/managers, and on a relatively low-skilled workforce, low levels of investments in innovation, lack of access to finance, and dependence on larger enterprises (either as suppliers or as clients). These characteristics influence the extent to which they can become socially and environmentally active and responsible. In particular, this will be affected by the motivations of the owners/managers, their background, and the reasons why they went into the business (for instance, to make a living, to apply their entrepreneurial skills, to become rich, etc).

Nevertheless, a new generation of entrepreneurs is developing within this general characterization. According to a recent study, this new generation is young, comes form the middle and upper-middle classes, is well educated, belongs to a family of business-persons or professionals, and is driven more by the desire of selfrealization than by the profit motive. These firms are still behind their European and Asian upstarts but have a different profile than the traditional Latin American SMEs. They are more oriented toward international markets; they are part of the value chain; their products are more likely to be differentiated, use of technology and as a result better performance in terms of employment and sales growth (Kantis et al., 2004). This new generation of SMEs is even more sensitive to community problems and has a more modern vision of business, in which environmental sustainability, concern for employees and wealth redistribution provide both ethical and economic returns. 


\section{Social and Environmental Responsibility in Small and Medium Enterprises in Latin America}

\section{THE SURVEY ${ }^{2}$}

This section reports on a comprehensive survey of 1,330 SMEs in eight Latin American countries. Approximately 150 to 215 firms were contacted in each country, the sample roughly consisting of two-thirds small firms (1 to 49 employees) and one-third medium firms (50 to 250 employees). ${ }^{3}$ The countries covered were Argentina, Brazil, Chile, Colombia, El Salvador, Mexico, Peru and Venezuela, which implies a broad geographical coverage and, to some extent, different levels of development. Most are middleincome countries where business owners and managers can be assumed to be somewhat familiar with CSR practices. The survey can be considered representative because it covers a large number of small and medium firms in each country. It may be argued that the number of employees used to define a medium firm in this survey is rather large for less developed countries. Nevertheless, the objective was to use the same definition of medium firms as in other studies to enhance comparability. Whenever the results differ between small and medium enterprises, they will be highlighted. The survey covers three types of firms: manufacture, commerce and services, with at least 50 firms of each type in each country. Regarding sectors of activity, care was taken in the selection of firms to avoid concentration on any one sector.

\footnotetext{
${ }^{2}$ The survey was carried out in 2004 by the Spanish consulting firm Ikei and eight partners in Latin America (seven universities and one consulting firm) for the Inter-American Development Bank. For the full results of the survey, see Vives et al. (2005).

${ }^{3}$ Needless to say, this is a very rough indicator of firm size and was used for the purposes of uniformity, as each country has its "official" definition. Dollar revenue had the problems of comparability between countries and confidentiality of information.
}

The results of the survey can be considered to be quite representative of the firms studied, although, as there are variations between countries, they may not apply to the rest of Latin America, especially the lower income countries. Another factor to take into consideration is that most firms surveyed were located in the capital city, thus results have an urban bias and they may not be representative of the situation in other geographical areas.

The survey was mainly conducted by means of personal interviews (in person or by phone); however, in some cases the questionnaire was sent electronically or by regular mail. The questionnaire used closed questions, i.e. answers were not open-ended or of the essay type. There was a total of 60 questions, each with multiple and very specific options. Only owners and/or managers were interviewed. It this regard, the responses represent their opinions, and as such they may be biased, a fact that must be kept in mind when interpreting results. It is not a survey of stakeholders or a measurement of the actual activities of SMEs.

In order to be able to establish comparisons with European countries, questions about external and environmental components of CSR (see next section) were the same as those in the survey of the European Commission, which was conducted by the same consulting firm. The European survey, though, did not cover the internal component, while our survey did.

\section{COMPONENTS OF CORPORATE SOCIAL RESPONSIBILITY IN SMES}

While the definition of corporate social responsibility differs by country, by CSR-promoting organizations, and even some individual firms will have their own interpretation, the survey asked very specific questions and avoided gen- 
eralizations. This, combined with the closed-end nature of the questions, makes the results robust, regardless of the CSR definition. The questions were directed to assess activities regarding the welfare of employees, firm governance, community support, and concern for the environment and the use of natural resource. The survey classified those practices as internal, external or environmental.

Internal responsibility refers to socially and environmentally responsible behavior as it relates to workers and suppliers. It is expressed in concern for the health and well-being of workers, their training and participation in the business, equality of opportunities, work-family relationship, and some corporate governance practices (independent audits, CSR in suppliers, internal control of corruption practices). External responsibility is defined as support for social and cultural community activities, as well as community development and other related issues. Environmental responsibility covers activities geared toward the reduction of the environmental impact of their operations, including such things as reducing waste and the consumption of natural resource, recycling, putting in place environmental management systems and the like.

\section{RESULTS OF THE SURVEY}

\section{Overall Results}

Firms were asked general questions on their commitment to the activities reported (specific questions in the survey will be detailed later). A high level commitment indicates that activities are part of the firm's strategy and are conducted on a routine basis. A medium level of commitment means that activities are routine, but they are not part of an overall strategy. A low level of commitment means that CSR activities are carried out only occasionally and on an ad hoc basis and are unrelated to the firm's strategy. Based on this rather coarse classification, the relative importance of the type of activities can be assessed by size and type of firm. Graph 1 shows that most firms carry out internal activities, while external and environmental efforts are less common. Because internal activities include a wide range of sometimes common actions, their ranking in the survey is not surprising. The

Graph 1: Level of Commitment by Area of Responsibility

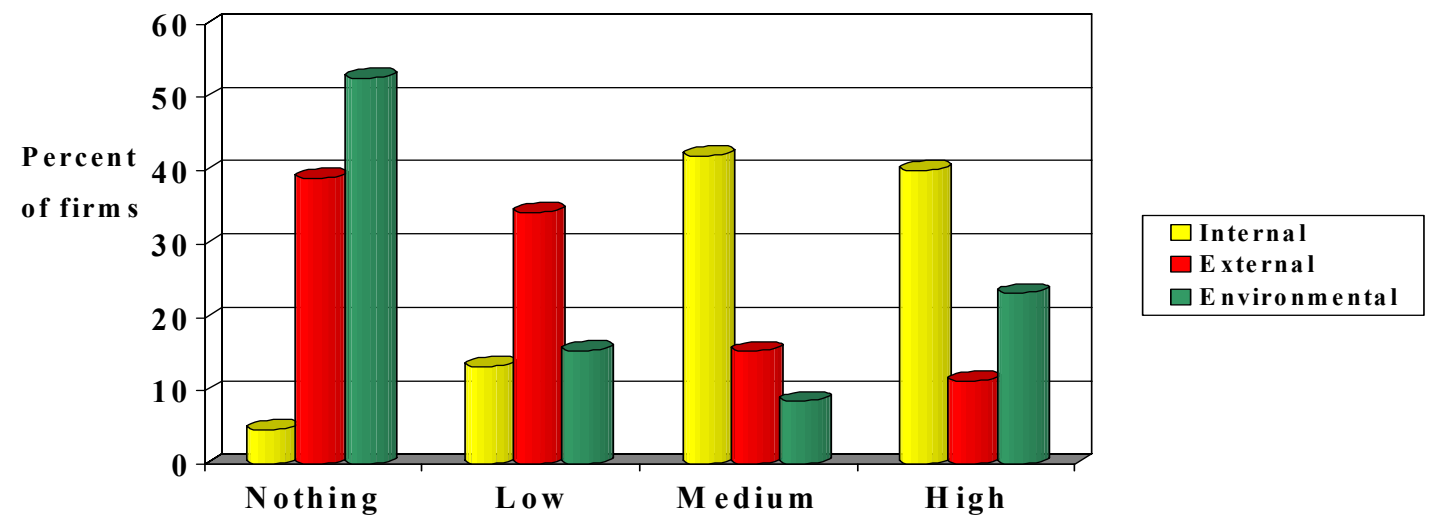




\section{Graph 2: High Level of Commitment by Size and Sector}

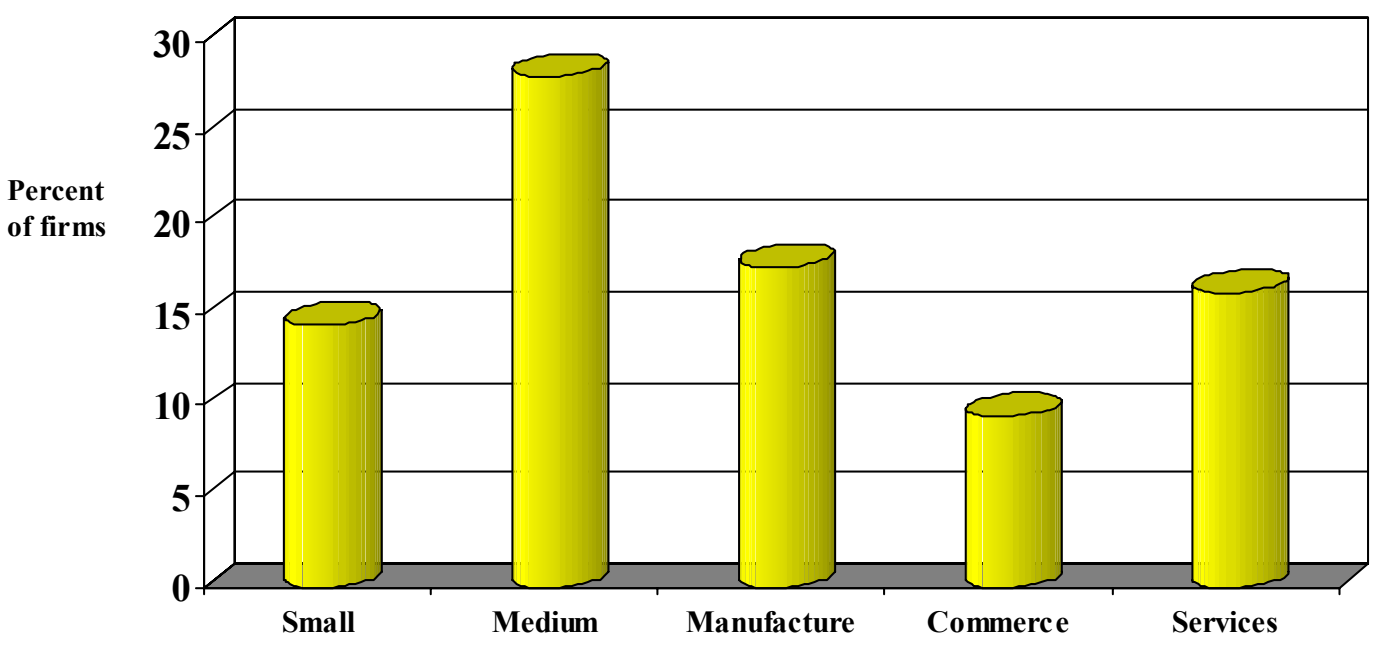

low ranking of environmental activities is also unsurprising given that they are issues of relatively recent concern. The level of commitment to external activities is rather low, possibly indicating their nonessential nature, as perceived by smaller firms, since they tend to be conducted only when needed or if the economic situation is favorable.

In Graph 2, which shows aggregate data by firm size, we see that smaller firms have a lower level of commitment than medium-sized firms (14.4 percent of small firms show a high level of commitment compared to 28 percent of medium-sized firms). By sector, the figure shows that those firms involved in commerce show a lower level of commitment to socially responsible practices than those in manufacturing and services (where one in six firms appear to be highly committed to CSR practices), presumably because of the lower visibility and impact of those practices. This will be seen in more detail below when results by type of activity are analyzed. Almost all firms, regardless of size and sector, report some activity in one of the areas of responsibility (less than 3 percent report no activity at all). An additional analysis was performed to compare firms that export their products to those that do not. As expected, exporters show a higher level of commitment to CSR practices, although the difference is most obvious in the case of medium and high levels of commitment. It is likely that exporters are more exposed to CSR practices and that this accounts to their higher level of commitment.

Graph 3 shows the high level of commitment by area of responsibility. Both small and mediumsized firms show the greatest level of commitment to internal CSR practices; while environmental practices take second place and external practices take third place. In all cases, mediumsized firms are more committed to all three types of CSR practices, especially in the case of ex- 


\section{Graph 3: High Level of Commitment by Size and Type}

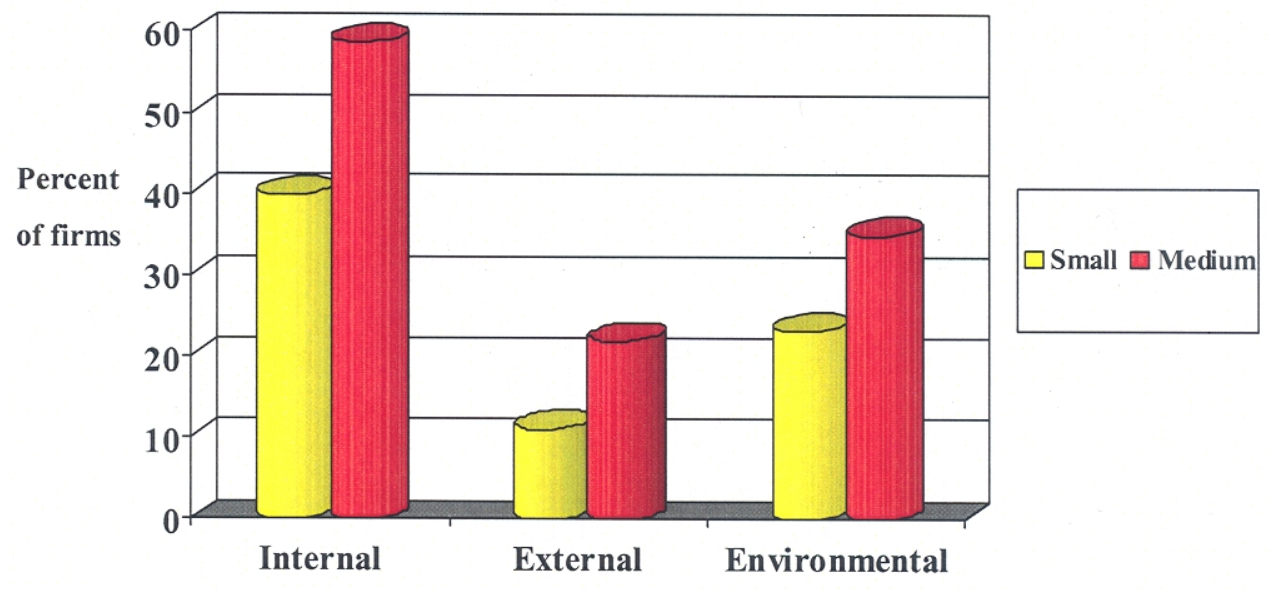

ternal responsibility, which appears to be twice that of small firms.

In terms of level of implementation by country, Graph 4 shows the percentage of firms that fall into the high/medium aggregate level of CSR activities. The graph shows that SMEs in Chile and Argentina have the highest level of CSR activity, while those in Brazil and El Salvador present the lowest. While the study did not attempt to analyze the reasons behind these differences, our assumption is that they are related to the relative openness of the respective economies (since, as noted earlier, firms that engage in exporting tend to implement more CSR practices), the level of development and, most importantly, cultural factors.

The survey included questions about the priority given to different CSR activities. While many firms appear to carry out socially and environmentally responsible activities, less than one third of them considered those activities to be a priority and less than one in eight thought that enough was being done. This seems to imply that while SMEs see the need for instituting CSR practices, they have not yet translate that into their corporate strategies in a systematic manner. We assume that the reason for this is that there is not enough understanding of the potential long-term benefits of these practices. Needless to say, this varies by size and type of firm, with exporters, manufacturers and medium-sized firms giving CSR practices and activities a higher priority. It also varies by country, with Chilean firms leading by a large margin, both in overall priority and satisfaction with the level of commitment to social and environmental issues. SMEs in Colombia and Brazil placed a lower priority on CSR practices, while those in Argentina, Brazil and Peru evinced a lower level of commitment.

A very interesting result, and one that bodes well for the future, is that almost three fourths of the firms believe that society in general is demanding more and more responsible behavior. Nevertheless, they do not perceive much pressure from their immediate stakeholders: workers, clients and suppliers. These results are almost uniform 
in all countries with the exception of Colombia, where all pressures pushing SMEs to increase their corporate social responsibility are rather weak, and Chile, where they are all strong or very strong.

\section{Internal Responsibility}

This area of corporate social responsibility was the most broadly defined and included the highest number of related questions in the survey; as a result, we anticipated some level of involvement in this category. Moreover, some level of activity in this area is expected because most SMEs will naturally be concerned about matters internal to the firm. Less that 5 percent of the firms reported that they do not engage in any internal CSR activities, while more than 40 percent of them showed a high level of involvement. As if to prove that activity in this area is almost a natural occurrence, but that many do it without conviction, more than forty percent also reported a low level of implementation. Among medium-sized firms we found a higher degree of implementation, but there was no noticeable dif- ference by sector (manufacturing, commerce and services) or by orientation (slightly higher for exporters than non-exporters). Argentina, Chile and Venezuela are the countries with the highest level of implementation, and Brazil and El Salvador present the lowest.

The areas of internal CSR with the highest degree of activity are, not surprisingly, workfamily issues, equity, health and well-being, and worker participation. Education ranked fourth, and corporate governance last, although some activities in these areas were reported by three fourths of firms. The CSR practices that appear most developed are respect for working hours (in 83.1 percent of firms), nondiscrimination and the provision of opportunities for dialogue. The least developed areas are verification of CSR practices in suppliers, benefit sharing and formal training programs (the latter was reported in only 13.4 percent of firms, even when most of them provide some form of access to training). Again, medium-sized firms tend to be more involved.

Graph 4: Level of Activity by Country

(percent of firms with high and medium levels)

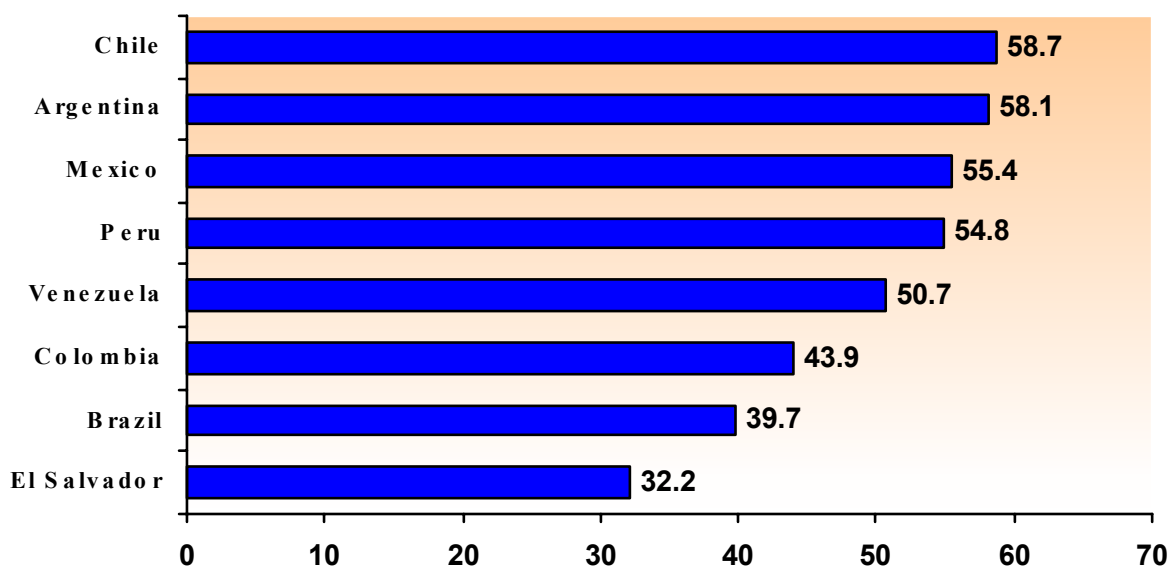




\section{External Responsibility}

Aggregate involvement in this area is the lowest. Only one in five of the medium-sized firms and one in ten of the small firms reported high involvement. Most CSR activities in this area tend to be targeted to cultural activities, sports, health and well-being, education, assistance to lowincome groups, and community participation. Medium-sized firms seem to be the most active in supporting sports (more than half of the medium-sized firms reportedly do so), health and cultural activities. Smaller firms show a bias toward education and providing assistance to low-income groups. Overall, assistance to lowincome groups is the most reported activity. These preferences may be related to the affinity of the smaller firms with the disadvantaged and the fact that medium-sized firms will usually have more resources available for such purposes. In Argentina, support went mostly to cultural activities, while in El Salvador and Peru it was concentrated on sports. In Chile, Mexico and Venezuela, low-income populations were the beneficiaries of support offered by firms.

In more than seventy percent of firms, external support was mainly in the form of donations through third parties (i.e. philanthropy without involvement, in cash and in kind). Management or employee involvement (donating time) is reported in roughly one third of the firms. The only noticeable difference by size of firm is in involvement by employees, where the proportion of medium-sized firms is almost twice that of small firms. Cash and in-kind donations are the single most important form of participation in all countries. The reported contribution varies between 0.36 percent of sales in Chile and 1.64 percent in Mexico.

\section{Environmental Responsibility}

To assess environmental responsibility, the survey covered activities related to the impact of the firm's operations on the environment, and covered issues such as impact monitoring, energy and water efficiency, waste reduction, recycling or treatment, taking advantage of byproducts, environmental management and verification of suppliers' responsibility.
Environmental responsibility was the area with least activity; indeed, more than half of the firms reported no activity at all in this area. Those firms that reported actively pursuing environmental CSR practices also report a "higher degree" of implementation that in external and internal responsibility. This is borne by other results that indicate that lack of activity of mostly due to lack of knowledge. Once the firm is aware or it is bound by regulations, it will tend to have a high degree of involvement. Mediumsized, manufacturing and exporting firms tend to have a higher degree of participation in environmental activities than smaller firms, firms in other sectors, and those that do not export. SMEs in Chile and Mexico reported the highest levels of implementation (around 40 percent of firms reported high or medium levels of implementation), while Brazil and El Salvador had the lowest (about 25 percent fell in the high and medium categories).

The most practiced activity is energy efficiency, followed by reduction, recycling and treatment of waste (both around half of firms). The least practiced activities are verification of suppliers' practices and an integrated environmental management system (less than 13 percent of the firms). Other practices, such as water conservation, monitoring and taking advantage of byproducts were reported by one in three of the firms.

\section{Driving Factors}

Why are firms carrying out these activities? It is generally assumed that the values of owner/managers and how close to or responsible for their employees and communities they feel will determine their level of social responsibility. Some of these assumptions are confirmed by the survey. The single most consistent reasons given for engaging in CSR practices were ethics and religious values (40 to 50 percent of the firms for all three categories of responsibility mentioned this motivation). ${ }^{4}$

\footnotetext{
${ }^{4}$ While we do not have comparable figures for larger firms, experience would tell us that this reason is very likely to be less important for larger, impersonal, firms and it would seem that this is a reason
} 
Graph 5: Driving Factors

(percent of firms reporting reasons)

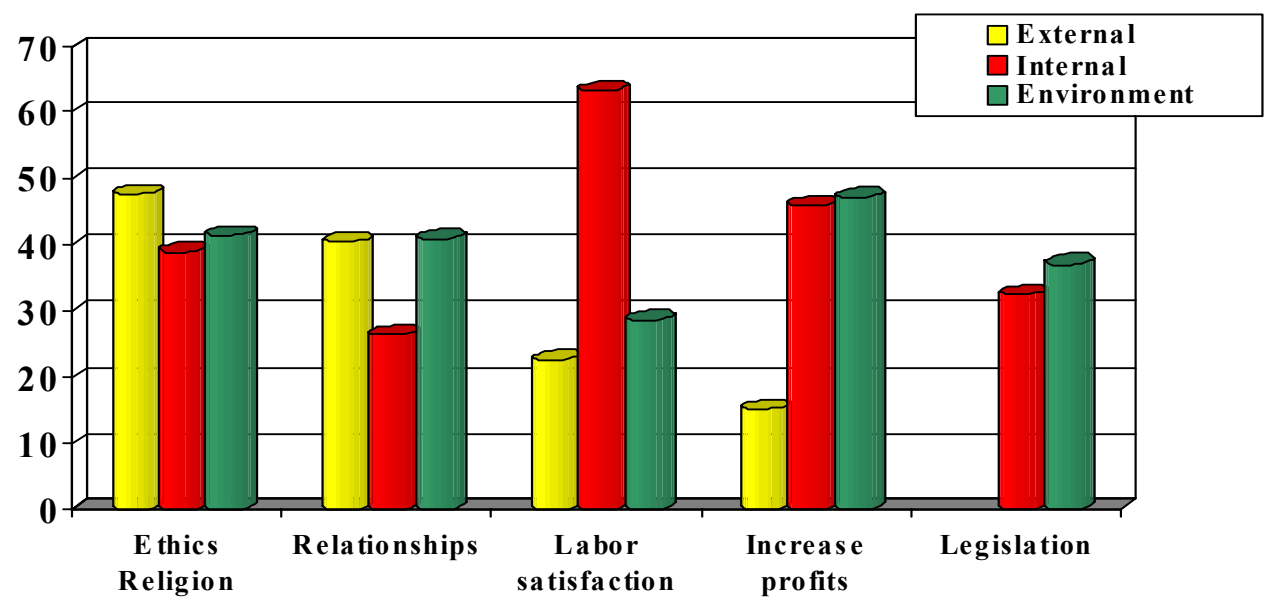

The welfare of employees was mentioned as the major reason for engaging in internal CRS practices (this may also be related to ethics and religious values and the desire to increase profits). Profits were mentioned as an important factor in engaging in internal and environmental (savings on resource consumption) CSR practices, in almost 47 percent in each case. Compliance with legislation was also reported as important for these two categories (32 and 37 percent respectively). Better relationships with the community and the public sector are also a consistent explanatory factor for all categories (mentioned by 26 to 41 percent of firms). Finally, the desire to improve relations with clients and suppliers was cited in all three categories, mostly for internal and environmental responsibility (23 to 39 percent, not shown in Graph 5). For medium-sized enterprises, profit, better relations and improving the welfare of employees are clearly stronger motives than for small firms.

It seems that corporate social responsibilities for Latin American SMEs are explained mostly by ethical and religious factors, concern for their

that clearly distinguishes SMEs from large firms regarding responsible behavior, although in our survey, it was not different for small and medium-sized firms. employees, the desire to improve profits and the need to maintain good relations with clients, suppliers and the community. Profits, while important, are one of many drivers, not much more important than other drivers. Pressure from civil society and public sector incentives do not seem to be as important.

\section{Obstacles to Responsibility}

Obstacles to a more active participation in external and environmental CSR practices are concentrated on lack of knowledge and resources. Lack of knowledge is cited by about 30 percent of the firms in each category of responsibility, while lack of resources is cited mostly as an obstacle to external responsibility. This is consistent with other results that show this activity as mostly altruistic, philanthropic and unrelated to the business itself, reflecting a lack of knowledge of the potential impact on the welfare of the firm. Additionally, an obstacle to involvement in environmental responsibility is the perceived lack of impact. This perception may also be a reflection of the lack of knowledge, because while it may be true that some firms may not have a direct measurable impact on the environment, all firms could optimize their resource use and handling of waste. Rather surprisingly, 


\section{Graph 6: Obstacles to Responsibility}

(percent of firms reporting reason)

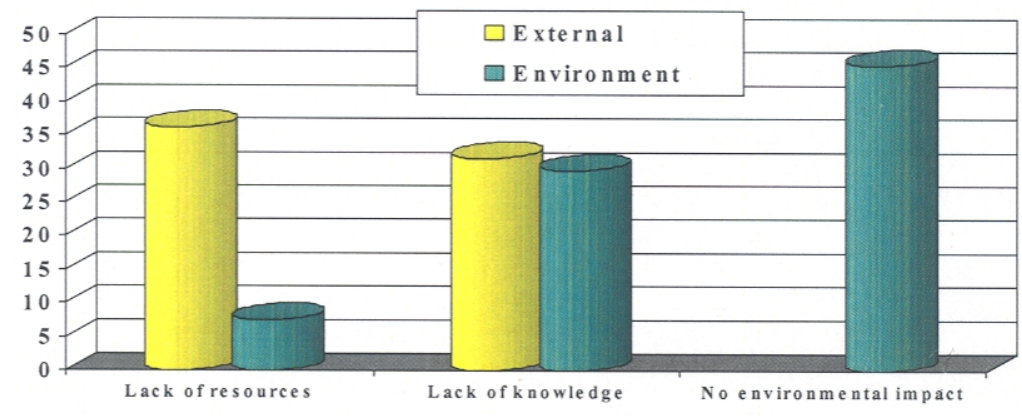

limitations in human resources, time and public support were not reported as obstacles by most firms. All of these results are rather uniform by country, size and type of firm. But one difference was found regarding lack of knowledge, which was cited more often by medium-sized firms (one explanation could be that the smaller firms do not know that they do not know). As most firms are engaged in internal CSR activities, related obstacles were not pursued in the survey.

\section{Future Involvement}

Regarding expectations for future involvement in CSR practices, the survey revealed relatively good intentions. Forty percent of firms that have a high degree of involvement (CSR is part of the firm's corporate strategy) stated that they intended to keep the same level of involvement, and about 50 percent indicated that they would probably increase it. Fifty percent of firms with a medium level of involvement (consistent with the firm's corporate strategy but not included in it) reported that they would maintain the same level of effort, while about 40 percent indicated that they would increase it. Even when these are only intentions, and "intentions for good behavior" are usually overestimated, there are encouraging signs that responsible practices may expand among Latin American SMEs. These results are consistent with opinions expressed in other parts of the survey, in the sense that SMEs are not doing enough in this regard. 


\section{Fostering Corporate Social Responsibility in SMEs}

Given the results of this survey and other studies, how can corporate social responsibility be promoted in SMEs? The most important barrier to overcome is the perception by many SME managers that being responsible is expensive, takes time and money. Many may see it simply as an expense, as they associate it with philanthropy and community involvement. Their lack of knowledge makes them unaware of the potential benefits of responsible behavior in the broader sense of a CSR strategy.

In order to engage SMEs, it may be better to build upon what they are already doing, deepening or widening their activities. For SMEs, it may not be a case of integrating CSR into the corporate strategy (in cases where one exists), as is the case for large corporations. Instead, it will require a more piecemeal, gradual approach to CSR issues, taking advantage of the ethical/religious reasons for involvement. As the survey results show, many SMEs are already engaged in what we would call corporate social responsibility, even if they do not call it by that name or are not even aware of the concept, or do not believe that they are explicitly engaged in those types of practices. Their involvement is informal, gradual, of the "one thing at a time" type, and almost unnoticeable. It need not involve large investments or recurring costs. Many of these activities have developed naturally, as a result of employee and community demands. Sometimes the best way to start is by appealing to the altruism of owners/managers and using the "feel good" argument. At some point in their careers, many may have been low-level employees themselves and, therefore, understand the importance and value of solidarity.

How should SME involvement be promoted? SMEs are close to the community and dependent on associations with similar businesses. As a result, the most useful sources of influence on them will be local governments, industry and commerce associations, and large buyers. The preferred method for involving them in CSR practices should be persuasion through encouragement and support. SMEs must be shown the value of involvement, but care must be exercised not to overstate it, as many of the actions taken by these firms may not ultimately have a direct or measurable impact. Another issue is that SME's information systems are not well developed and, as a result, they may not be able to establish causality.

SME involvement can be fostered with the use of simple tools. For instance, one of the most effective ways to do so is by disseminating examples of practices employed by their peers. Also useful will be making guidelines, checklists and examples available to them, preferably prepared and presented by institutions and individuals that are not attempting to sell them anything but simply share similar views. Because, in some cases, SMEs are not sophisticated and do not have the resources or talent to devote to CSR issues, it is important that the strategy of engagement be as simple as possible, promoting one goal at a time. SMEs may face many barriers to adopting CSR practices, including lack of resources, especially the limited time that owners or managers can devote to these activities, and the knowledge or awareness of the opportunities afforded by these practices. Moreover, involvement in CSR practices should not be regarded as an obligation or regulation if a strong conviction about the long-term benefits of responsibility is to be developed among SMEs.

\section{CONCLUDING REMARKS}

While the survey found that responsible practices are rather common in SMEs, there is still a need to deepen the involvement of those already practicing CSR and promote it among those SMEs that are not yet participating in such efforts. SMEs, by their nature, particularly in terms of governance, ownership and goals, are a fertile ground for the development of responsible behavior. 
The traditional tools and methods for involvement were developed mostly for larger firms in developed economies, for which the business case may the most effective instrument. For smaller firms in developing countries, the promotion of responsible practices must built on the ethical/religious motivation already existing to make the busi- ness case, wherever possible, which in turn will help to ensure sustainability of this behavior as firms evolve and face more competitive pressures. The findings of the survey, which are summarized here, may help determine the areas where actions are most likely to be effective. 


\section{References}

Kantis, H., M. Ishida, and M. Komori. 2002. Entrepreneurship in Emerging Economies: The Creation and Development of New Firms in Latin American and East Asia. Washington, D.C.: InterAmerican Development Bank.

Kantis, H., P. Angelelli, and V. Koening. 2004. Developing Entrepreneurship: Experience in Latin American and Worldwide. Washington, D.C.: Inter-American Development Bank.

Spence, L. 2000. Priorities, Practice and Ethics in Small Firms. London: Institute of Business Ethics.

Vives, A., A. Corral and I. Isusi. 2005. Responsabilidad social de la empresa en las PyMEs de Latinoamerica. Washington, D.C.: Inter-American Development Bank. Available at www.csramericas.org. 